\title{
Polymorphisms in IL-1 $\beta$, vitamin D receptor Fok1, and Toll-like receptor 2 are associated with extrapulmonary tuberculosis
}

\author{
Alison A Motsinger-Reif ${ }^{1 \dagger}$, Paulo RZ Antas ${ }^{2 \dagger}$, Noffisat O Oki ${ }^{1}$, Shawn Levy ${ }^{3}$, Steven M Holland ${ }^{4}$, \\ Timothy R Sterling ${ }^{2,5^{*}}$
}

\begin{abstract}
Background: Human genetic variants may affect tuberculosis susceptibility, but the immunologic correlates of the genetic variants identified are often unclear.

Methods: We conducted a pilot case-control study to identify genetic variants associated with extrapulmonary tuberculosis in patients with previously characterized immune defects: low CD4+ lymphocytes and low unstimulated cytokine production. Two genetic association approaches were used: 1) variants previously associated with tuberculosis risk; 2) single nucleotide polymorphisms (SNPs) in candidate genes involved in tuberculosis pathogenesis. Single locus association tests and multifactor dimensionality reduction (MDR) assessed main effects and multi-locus interactions.

Results: There were 24 extrapulmonary tuberculosis cases (18 black), 24 pulmonary tuberculosis controls (19 black) and 57 PPD+ controls (49 black). In approach 1, 22 SNPs and 3 microsatellites were assessed. In single locus association tests, interleukin (IL)-1 $\beta+3953 \mathrm{C} / \mathrm{T}$ was associated with extrapulmonary tuberculosis compared to PPD+ controls $(P=0.049)$. Among the sub-set of patients who were black, genotype frequencies of the vitamin $D$ receptor (VDR) Fok1 A/G SNP were significantly different in extrapulmonary vs. pulmonary TB patients $(P=0.018)$. In MDR analysis, the toll-like receptor (TLR) 2 microsatellite had 76\% prediction accuracy for extrapulmonary tuberculosis in blacks $(P=0.002)$. In approach 2, 613 SNPs in 26 genes were assessed. None were associated with extrapulmonary tuberculosis.
\end{abstract}

Conclusions: In this pilot study among extrapulmonary tuberculosis patients with well-characterized immune defects, genetic variants in IL-1 $\beta$, VDR Fok1, and TLR2 were associated with an increased risk of extrapulmonary disease. Additional studies of the underlying mechanism of these genetic variants are warranted.

\section{Background}

A possible genetic predisposition to tuberculosis has been suggested in several studies,[1-3] but the functional immunologic correlate of the genetic polymorphisms identified is often unclear[4]. We have sought to first identify immunologic defects that may predispose to tuberculosis, then assess for genetic polymorphisms associated with these immunologic defects. Because there is evidence that extrapulmonary tuberculosis is the

\footnotetext{
* Correspondence: timothy.sterling@vanderbilt.edu

† Contributed equally

${ }^{2}$ Division of Infectious Diseases, Department of Medicine, Vanderbilt University School of Medicine, Nashville, TN, USA
}

result of an underlying immune defect, [5] we have focused our search on persons with prior extrapulmonary disease. In previous studies we noted that HIV-seronegative adults with prior extrapulmonary tuberculosis had lower levels of CD4+ lymphocytes, unstimulated cytokine production, and tumor necrosis factor (TNF)- $\alpha$ production in response to lipopolysaccharide (LPS) or LPS + interferon (IFN)- $\gamma$ than persons with prior pulmonary tuberculosis or latent $M$. tuberculosis infection $[6,7]$.

In the current study we have combined two previous study populations in which cytokine responses were well-characterized, $[6,7]$ to identify genetic 
polymorphisms associated with extrapulmonary tuberculosis, and by extension, the associated immunologic abnormalities. We make use of a candidate gene approach utilizing single nucleotide polymorphisms (SNPs) and microsatellites previously reported to be associated with tuberculosis, and we also include SNPs in candidate genes that are hypothesized to play a role in tuberculosis pathogenesis.

Because several loci could contribute to the phenotype expressed in complex diseases such as tuberculosis, it is important to search for gene-gene interactions (epistasis), which may give a more accurate prediction of disease risk. Such interactions are difficult to detect using traditional statistical methods such as single locus association tests because those tests were not developed to detect purely interactive effects. Such tests identify genes with main effects and then follow-up analyses assess for interactions between genes that exhibit a main effect. New statistical and computational methods that have better power to detect interactions, including those without main effects, in relatively small sample sizes, are required. Multifactor dimensionality reduction (MDR) analysis is a novel method developed to address this need[8]. In the current study both single locus association tests and MDR analysis were used to detect potential single or multi-locus interactions that predict extrapulmonary tuberculosis.

\section{Results}

\section{Clinical and Demographic Characteristics}

There were 24 extrapulmonary tuberculosis cases (18 black), 24 pulmonary tuberculosis controls (19 black), and 57 controls (49 black) with latent M. tuberculosis infection. The clinical and demographic characteristics of the study population are in Table 1 . There were no significant differences between cases and controls according to age, sex, or race. However, pulmonary controls had lower median body mass index (BMI) at the time of study than either extrapulmonary tuberculosis cases or controls with latent $M$. tuberculosis infection. Extrapulmonary tuberculosis cases had lower median CD4+ lymphocytes at time of study than controls. The sites of disease among extrapulmonary cases included lymphatic $(n=9)$, pleural $(n=4)$, bone/joint $(n=4)$, pericardial $(n=2)$, genito-urinary $(n=2)$, miliary/ meningeal $(n=1)$, gastrointestinal $(n=1)$, and laryngeal $(\mathrm{n}=1)$.

\section{SNPs Associated with Tuberculosis in Previous Studies}

Of the 27 SNPs and 3 microsatellites previously reported in the literature as being associated with tuberculosis (Table 2), 25 SNPs and all 3 microsatellites were assessed by PCR-based SNP genotyping. The IL-1 $\beta-511$ $(\mathrm{C} \rightarrow \mathrm{T})$ and vitamin $\mathrm{D}$ receptor (VDR) Bsm 1 SNPs were on the GeneChip ${ }^{\oplus}$ Human Mapping 50K Xba Array. Of the 30 polymorphisms tested, 5 SNPs (rs 17235416, rs1800450, rs5743708, rs6265786, rs2393799) were unable to be genotyped after quality control and were therefore excluded. Only markers with $<10 \%$ missing data were considered for analysis. No imputation of missing values was performed. For univariate analyses, missing values were removed for analysis; for the MDR analysis, missing observations were ignored, such that attribute construction and accuracy calculations were only performed based on observed values.

In single locus association testing of each polymorphism among all study participants, the IL- $1 \beta+3953$ $(\mathrm{C} \rightarrow \mathrm{T})$ SNP was associated with any tuberculosis $(\mathrm{P}=$ $0.044)$ and extrapulmonary tuberculosis $(\mathrm{P}=0.049)$ compared to PPD+ controls (Table 3). Among black patients, the Fok1 SNP in the VDR gene was associated with extrapulmonary tuberculosis compared to pulmonary tuberculosis controls $(\mathrm{P}=0.018)$.

In MDR analysis of the 25 polymorphisms among all study participants, the microsatellite in TLR2 (GT) had $61 \%$ prediction accuracy for any tuberculosis compared to controls with $M$. tuberculosis infection $(\mathrm{P}=0.038)$ (Table 3 ). It also had $63 \%$ prediction accuracy for any

Table 1 Clinical and Demographic Characteristics of the Study Population

\begin{tabular}{|c|c|c|c|c|}
\hline Characteristic & Extrapulmonary TB $(n=24)$ & Pulmonary TB $(n=24)$ & PPD+ $(n=57)$ & P value ${ }^{a}$ \\
\hline Age at study entry (years) & $\begin{array}{c}48.4 \\
(43.6-79.4)\end{array}$ & $\begin{array}{c}43.6 \\
(40.3-53.9)\end{array}$ & $\begin{array}{c}45.7 \\
(38.8-53.3)\end{array}$ & 0.18 \\
\hline \# Male Sex (\%) & $16(67)$ & $14(58)$ & $36(63)$ & 0.84 \\
\hline \# Black Race (\%) & $18(75)$ & $19(79)$ & $49(86)$ & 0.46 \\
\hline \# White Race (\%) & $4(17)$ & $4(17)$ & $8(14)$ & 0.93 \\
\hline \# Asian Race (\%) & $2(9)$ & $1(4)$ & $0(0)$ & 0.11 \\
\hline BMl at study entry $\left(\mathrm{kg} / \mathrm{m}^{2}\right)$ & $\begin{array}{c}25.5 \\
(23.0-29.6)\end{array}$ & $\begin{array}{c}20.6 \\
(18.2-24.0)\end{array}$ & $\begin{array}{c}25.9 \\
(22.8-30.5)\end{array}$ & $<0.001$ \\
\hline CD4 count at study entry & $\begin{array}{c}701 \\
(565-1015)\end{array}$ & $\begin{array}{c}814 \\
(594-938)\end{array}$ & $\begin{array}{c}879 \\
(703-1114)\end{array}$ & 0.05 \\
\hline
\end{tabular}

Data are medians (inter-quartile range; IQR) except as noted.

${ }^{a}$ Kruskal-Wallis test for continuous variables; Chi-square test for categorical variables. 
Table 2 Polymorphisms Tested that had Previously Been Reported as Associated with Tuberculosis

\begin{tabular}{|c|c|c|c|}
\hline Gene & SNP & rs number & References \\
\hline \multirow{5}{*}{$\begin{array}{l}\text { NRAMP1 } \\
\text { (SIc11a1) }\end{array}$} & $5^{\prime}(G T)_{n}$ microsatellite & -——- - & {$[1,22-26]$} \\
\hline & INT4 (469+14G/C) & rs3731865 & {$[1,26]$} \\
\hline & D543N & rs17235409 & {$[1,27,24,28,26]$} \\
\hline & 3'UTR (1729+55del4) & rs17235416 & {$[1,27,28,26]$} \\
\hline & $274 C / T$ & rs2276631 & {$[29]$} \\
\hline \multirow[t]{2}{*}{ SP110 } & sp110 intron 6 & rs2114592 & {$[30]$} \\
\hline & sp110 exon 11 & rs3948464 & {$[30]$} \\
\hline \multirow{4}{*}{$\begin{array}{l}\text { IL-12/23/IFN- } \gamma \\
\text { Pathway }\end{array}$} & $+874 \mathrm{~A} / \mathrm{T}$ & rs2430561 & {$[31-35]$} \\
\hline & $-1616 G$ & rs2069705 & {$[36]$} \\
\hline & $+3234 \mathrm{~T}$ & rs2069718 & {$[36]$} \\
\hline & IFNGR1 $-56 C / T$ & rs2234711 & [36] \\
\hline \multirow{4}{*}{$\begin{array}{l}\mathrm{IL}-1 \text { and IL-1 } \\
\text { RA }\end{array}$} & IL-1 $\alpha-899 \mathrm{C} / \mathrm{T}$ & rs1800587 & [37] \\
\hline & $\mathbb{I L}-1 \beta+3953 C / T$ & rs1143634 & {$[38]$} \\
\hline & $I L-1 \beta-511 C / T$ & rs16944 & [39] \\
\hline & IL-1RA microsatellite & & {$[40]$} \\
\hline \multirow[t]{2}{*}{ IL-10 } & $-1082 \mathrm{G} / \mathrm{A}$ & rs1800896 & {$[41,34,42]$} \\
\hline & $-592 \mathrm{~A} / \mathrm{C}$ & rs1800872 & {$[43]$} \\
\hline \multirow[t]{3}{*}{ MBL } & $\begin{array}{l}\text { Codon } 52 \mathrm{C} / \mathrm{T} \text { (allele } \\
\text { D) }\end{array}$ & rs5030737 & [44] \\
\hline & $\begin{array}{l}\text { Codon } 54 \text { A/G (allele } \\
\text { B) }\end{array}$ & rs1800450 & [44] \\
\hline & $\begin{array}{l}\text { Codon } 57 \mathrm{~A} / \mathrm{G} \text { (allele } \\
\text { C) }\end{array}$ & rs1800451 & {$[44]$} \\
\hline \multirow[t]{3}{*}{ VDR } & Taq1 $\mathrm{C} / \mathrm{T}$ & rs731236 & {$[11,2,45]$} \\
\hline & Fok1 A/G & rs10735810 & {$[11,28]$} \\
\hline & Bsm 1 & rs154410 & {$[45]$} \\
\hline MCP-1 & $-2518 \mathrm{~A} / \mathrm{G}$ & rs1024611 & {$[46]$} \\
\hline TIRAP & C558T & rs7932766 & [47] \\
\hline \multirow[t]{3}{*}{ TLR2 } & $\begin{array}{l}\text { GT repeat intll } \\
\text { microsatellite }\end{array}$ & -——- & [18] \\
\hline & Arg753Gln & rs5743708 & {$[48]$} \\
\hline & Arg677Trp & rs6265786 & [49] \\
\hline \multirow[t]{2}{*}{$P 2 \times 7$} & $-762 \mathrm{~T} / \mathrm{C}$ & rs2393799 & {$[50]$} \\
\hline & $1513 \mathrm{~A} / \mathrm{C}$ & rs3751143 & [51] \\
\hline
\end{tabular}

Polymorphisms were reported in the literature prior to November 15, 2006. There were 27 single nucleotide polymorphisms (SNPs) and three microsatellites. The status of each polymorphism tested in this study is provided.

Abbreviations (names of genes):

NRAMP-1 natural resistance-associated macrophage protein-1

SP110 speckled 110, nuclear hormone receptor co-activator

IL-12/23 interleukin-12/23

IFN- $\gamma$ interferon-gamma

IFNGR1 interferon-gamma receptor 1

VDR vitamin D receptor

IL-1 interleukin-1

MCP-1 monocyte chemoattractant protein-1

IL-1 RA interleukin-1 receptor antagonist

TIRAP toll-interleukin 1 receptor adapter protein

IL-10 interleukin-10

TLR2 toll-like receptor 2

MBL mannose binding lectin

P2X7 purinoreceptor
Table 3 Of the Polymorphisms Tested that had

Previously Been Reported as Associated with

Tuberculosis (Table 2), the SNPs Associated with

Tuberculosis in this Study

\begin{tabular}{|c|c|c|}
\hline Comparator groups & SNPs & P-value \\
\hline \multicolumn{3}{|c|}{ Single Locus Association Tests } \\
\hline \multicolumn{3}{|l|}{ All patients } \\
\hline Any TB vs. PPD+ & IL-1 beta +3953 & 0.044 \\
\hline ExtTB vs. PPD+ & IL-1 beta +3953 & 0.049 \\
\hline ExtTB vs. PulmTB & none & - \\
\hline \multicolumn{3}{|l|}{ Black patients } \\
\hline Any TB vs. PPD+ & none & - \\
\hline ExtTB vs. PPD+ & none & - \\
\hline ExtTB vs. PulmTB & VDR Fok1 & 0.018 \\
\hline \multicolumn{3}{|c|}{ Multifactor Dimensionality Reduction Analysis } \\
\hline \multicolumn{3}{|c|}{ All patients } \\
\hline Any TB vs. PPD+ & TLR2 microsatellite & $0.038 \#$ \\
\hline ExtTB vs. PPD+ & none & - \\
\hline ExtTB vs. PulmTB & none & - \\
\hline \multicolumn{3}{|l|}{ Black patients } \\
\hline Any TB vs. PPD+ & TLR2 microsatellite & $0.047^{*}$ \\
\hline ExtTB vs. PPD+ & TLR2 microsatellite & $0.002^{\wedge}$ \\
\hline ExtTB vs. PulmTB & none & - \\
\hline
\end{tabular}

SNPs with $\mathrm{P} \leq 0.05$ are listed. $\mathrm{P}$-values are uncorrected.

\# $61 \%$ prediction accuracy

* $63 \%$ prediction accuracy

$\wedge 76 \%$ prediction accuracy

tuberculosis in blacks $(\mathrm{P}=0.047)$ and $76 \%$ prediction accuracy for extrapulmonary tuberculosis in blacks $(\mathrm{P}=$ 0.002). Results did not change when the analysis included CD4+ lymphocytes and BMI as potential covariates (results not shown).

\section{SNPs in Candidate Genes}

There were 661 SNPs in genes presumed to be associated with tuberculosis pathogenesis (Table 4), of which 613 (93\%) had genotyping efficiency $>90 \%$ (i.e., $<10 \%$ missing data) and were included in the analysis. In the MDR analysis of these 613 SNPs, an intronic SNP in TNF- $\alpha$ $(\mathrm{C} \rightarrow \mathrm{T})(\mathrm{rs} 1811063)$ predicted tuberculosis with $62 \%$ accuracy among all patients $(P=0.05$; Table 5$)$. The combination of two SNPs in TLR4 $(\mathrm{C} \rightarrow \mathrm{T})$ (rs1399431) and TNF- $\alpha(\mathrm{C} \rightarrow \mathrm{T})$ (rs7791836) predicted tuberculosis risk with $71 \%$ accuracy in blacks $(P=0.02)$. Results did not change when the analysis included CD4+ lymphocytes and BMI as potential covariates (results not shown). There were no SNPs associated with extrapulmonary tuberculosis compared to controls.

\section{Discussion}

In this study population we first identified immunologic defects among persons with extrapulmonary tuberculosis, then explored possible associations with candidate 


\begin{tabular}{|c|c|c|c|c|c|}
\hline Gene & \# SNPs & Gene & \# SNPs & Gene & \# SNPs \\
\hline $\mid L-4$ & 4 & GATA3 & 68 & $\mathrm{IFN}-\alpha$ & 5 \\
\hline IL-6 & 11 & TRAF6 & 3 & CYLD & 13 \\
\hline |L-8 & 5 & HLA-DQ & 5 & BCL10 & 1 \\
\hline |L-10 & 4 & HLA-DR & 5 & A20 & 28 \\
\hline IL-12 & 28 & VDR & 2 & TAK1 & 7 \\
\hline TNF & 191 & NOD2/CARD15 & 1 & STAT4 & 9 \\
\hline IFN- $\gamma$ & 18 & $\mathrm{NF} \kappa \mathrm{b}$ & 50 & IL-23 & 6 \\
\hline $\mid L-1 \beta$ & 2 & STAT1 & 3 & TLR4 & 21 \\
\hline RunX & 66 & TGF- $\beta$ & 105 & & \\
\hline
\end{tabular}

The number of SNPs tested in each gene is provided. There were a total of 661 SNPs.

Table 5 Of the SNPs Listed in Table 4, the SNPs Associated with Tuberculosis in This Study Population

\begin{tabular}{|c|c|c|c|c|c|}
\hline $\begin{array}{l}\text { RS } \\
\text { number }\end{array}$ & Gene & $\begin{array}{l}\text { Minor } \\
\text { Allele } \\
\text { Frequency }\end{array}$ & $\begin{array}{l}\text { Average } \\
\text { Testing } \\
\text { Balanced } \\
\text { Accuracy }\end{array}$ & $\begin{array}{l}\text { Cross- } \\
\text { validation } \\
\text { Consistency }\end{array}$ & P-value \\
\hline
\end{tabular}

Any TB vs. PPD+, all patients

$62.11^{\#} \quad 4 / 5$

0.05

Any TB vs. PPD+, black patients

$\begin{array}{llllll}\text { Rs1399431 } & \text { TLR4 } & 0.401 & 71.27^{\wedge} & 3 / 5 & 0.02 \\ \text { Rs7791836 } & \text { TNF- } \alpha & 0.5 & & \end{array}$

\#Testing Sensitivity: 0.55 ; Testing Specificity: 0.69

$\wedge$ Testing Sensitivity: 0.71; Testing Specificity: 0.72 . In post-hoc logistic regression analysis using these 2 SNPs, a recessive encoding for each SNP maximized the model fit.

The above are Multifactor Dimensionality Reduction models. Only models with $\mathrm{P} \leq 0.05$ are presented here.

genetic variants. In single locus association tests among genetic variants previously associated with tuberculosis susceptibility, IL-1 $\beta+3953$ was associated with extrapulmonary disease, as well as all forms of tuberculosis, compared to persons with M. tuberculosis infection. Among black patients, the Fok1 SNP in the VDR gene distinguished extrapulmonary from pulmonary disease. The MDR analysis provides important additional results, however, because it is more powerful than traditional logistic regression analysis,[9] adjusts for multiple comparisons via permutation testing, and because the results were more consistent across the groups assessed. MDR also evaluates potential gene-gene and gene-environment interactions, which are important to investigate in complex phenotypes such as tuberculosis pathogenesis. The TLR2 microsatellite predicted extrapulmonary tuberculosis in black patients with $76 \%$ accuracy. It also predicted all forms of tuberculosis in blacks, as well as in the full study population. The prediction accuracy estimates the importance of variables in the dataset, with the intent of generalizing the model to the full population.
These results point to the importance of IL- $1 \beta+3953$, VDR Fok1 A/G, and the TLR2 microsatellite in extrapulmonary tuberculosis risk, with the latter two being particularly significant in blacks, even in such a small sample size. This is important in light of the increased proportion of extrapulmonary tuberculosis in blacks[5]. Further studies are needed to determine if these polymorphisms could account for this epidemiological finding. This study included very few individuals of other racial backgrounds, making comparisons of genetic models between racial groups impossible. Our results are consistent with the previously noted association between IL-1 $\beta+3953$ and tuberculous pleurisy, and VDR Fok1 and several forms of extrapulmonary tuberculosis-both noted among in Gujarati Asians living in London[10,11]. They are also consistent with the recently identified link between TLR and the innate immune response to $M$. tuberculosis: the relationship between TLR signaling, the up-regulation of the VDR, and vitamin D-mediated killing of intracellular $M$. tuberculosis via the microbial peptide cathelicidin[12]. In that study, blacks had low 25-hydroxyvitamin D levels and low cathelicidin messenger RNA induction. While immediate biological interpretation of our results is not possible, defects in $M$. tuberculosis recognition and/or subsequent intracellular signaling in the nuclear factor kappa B $(\mathrm{NF}-\kappa \mathrm{B})$ pathway related to TLR2 polymorphisms would be consistent with the subtle innate immune defects in the extrapulmonary tuberculosis patients in this study population: low unstimulated cytokine production, decreased TNF- $\alpha$ production in response to LPS or LPS + IFN- $\gamma$, and low CD4+ lymphocytes $[6,7,4]$.

The results from SNPs in genes hypothesized to play a role in tuberculosis pathogenesis showed that no SNPs were significantly associated with extrapulmonary tuberculosis. There was, however, a SNP in TNF- $\alpha$ that was associated with tuberculosis among all study participants. And among blacks, a combination of SNPs in TNF- $\alpha$ and TLR4 predicted tuberculosis risk with $71 \%$ accuracy. These SNPs cannot be interpreted as easily in light of the immunologic findings, which pertain to extrapulmonary tuberculosis. However, they suggest that similar cytokine pathways as those noted above are important in tuberculosis pathogenesis.

It was notable that persons with prior extrapulmonary tuberculosis or latent $M$. tuberculosis infection had significantly higher body mass index (BMI) than persons with pulmonary tuberculosis. If BMI after completion of treatment is comparable to BMI prior to development of disease, it would suggest that lower BMI may predispose to pulmonary tuberculosis. It should be noted that the median BMI in persons with pulmonary disease was within the normal range, whereas BMI in persons in the other two groups was high. A recent large population- 
based study in Hong Kong found that as BMI increased, the risk of pulmonary tuberculosis decreased, but the risk of extrapulmonary tuberculosis did not[13]. The protective effect of increased BMI on pulmonary disease in that study persisted even after controlling for confounding variables, including smoking and diabetes mellitus. The above findings suggest that risk factors for extrapulmonary tuberculosis are not ameliorated by increased BMI-which would be consistent with an immunogenetic predisposition to extrapulmonary tuberculosis. Factors related to the M. tuberculosis strain also play a role in extrapulmonary disease[14].

The most important limitation of the current study was the small sample size. This was driven by the intensive immunologic testing performed on specimens from each participant. Statistically significant genetic associations were indeed identified, but the sample was underpowered (with either traditional methods or MDR analysis) to detect other potential associations. Additionally, even for the positive associations detected, reliable estimates of effect size cannot be determined, due to the "winner's curse" related to the small sample size[15]. Table 6 shows the detectable effect sizes with the current sample size for the variants previously associated with tuberculosis. These calculations assume $80 \%$ power and an uncorrected alpha of $0.05 \%$. Larger studies are

\begin{tabular}{|c|c|c|c|}
\hline SNP & rs number & $\begin{array}{l}\text { Minor Allele } \\
\text { Frequency }\end{array}$ & $\begin{array}{l}\text { Detectable } \\
\text { Odds Ratio* }\end{array}$ \\
\hline NRAMP1 INT4 & rs3731865 & 0.12 & 4.19 \\
\hline NRAMP1 D543N & rs17235409 & 0.07 & 5.42 \\
\hline NRAMP1 $274 \mathrm{C} / \mathrm{T}$ & rs2276631 & 0.19 & 3.56 \\
\hline SP 110 & rs2114592 & 0.15 & 3.85 \\
\hline SP 110 & rs3948464 & 0.13 & 4.06 \\
\hline $\mathrm{IFNg}+874 \mathrm{~A} / \mathrm{T}$ & rs2430561 & 0.29 & 3.26 \\
\hline IFNg -1616G & rs2069705 & 0.49 & 3.41 \\
\hline IFNg +3234 & rs2069718 & 0.43 & 3.27 \\
\hline IFNgR1 $-56 \mathrm{C} / \mathrm{T}$ & rs2234711 & 0.45 & 3.31 \\
\hline IL-1a -889 C/T & rs1800587 & 0.38 & 3.22 \\
\hline IL-1B +3953 C/T & rs1143634 & 0.12 & 4.19 \\
\hline IL-10 -1082 G/A & rs1800896 & 0.35 & 3.21 \\
\hline IL-10 -592 A/C & rs1800872 & 0.42 & 3.26 \\
\hline MBL codon 57 & rs1800451 & 0.15 & 3.85 \\
\hline VDR Taq1 & rs731236 & 0.26 & 3.31 \\
\hline VDR Fok1 A/G & rs10735810 & 0.23 & 3.39 \\
\hline MCP-1 -2518 A/G & rs1024611 & 0.19 & 3.56 \\
\hline TIRAP C558T & rs7932766 & 0.17 & 3.69 \\
\hline P2X7 $1513 \mathrm{~A} / \mathrm{C}$ & rs3751143 & 0.12 & 4.19 \\
\hline
\end{tabular}

These calculations assume $80 \%$ power. This table includes SNPs that have previously been reported to be associated with tuberculosis.

*Odds ratios greater than this value could have been detected in this study. needed in which candidate gene polymorphisms and associated cytokine pathways are fully evaluated in all patients, so that any genetic polymorphisms identified can be interpreted in the context of the cytokine abnormalities noted. Given this, one should consider the results of this study-particularly those from the candidate gene approach and interaction analysis-as hypothesis-generating rather than hypothesis-confirming. While MDR has greater statistical power than traditional methods, its power to detect gene-gene and gene-environment interactions is less than that to detect main effects. In searching for interactive effects, the small sample size did not allow for investigating interactions with more than two loci.

There were other limitations of this study. First, of the SNPs tested that had previously been associated with tuberculosis, most pertained to pulmonary rather than extrapulmonary disease. Due to possible differences in the pathophysiology of these two disease manifestations, [7] one might expect that not all of the SNPs tested would be related to the pathogenesis of extrapulmonary tuberculosis. Second, not all genes that are presumably associated with tuberculosis pathogenesis had SNPs included in the GeneChip ${ }^{\odot}$ Human Mapping $50 \mathrm{~K}$ Xba Array, so not all such genes could be assessed. Third, we were unable to directly incorporate cytokine response data into the genetic analyses because the methodology used to quantify cytokine responses was not the same in the two immunologic studies.

Additionally, concerns with multiple testing arise when screening such a large number of genetic variants. The results of the first approach are presented without any corrections for multiple testing. Because these variants have been associated with tuberculosis before, each test represents an independent statistical hypothesis. By using MDR and permutation in the second approach, $\mathrm{P}$ values were empirically derived based on the total number of tests at each stage.

\section{Conclusions}

The results of this study suggest that an evaluation of the underlying mechanism(s) of the genetic variants in IL- $\beta+3953$, VDR Fok1 A/G, and the TLR2 microsatellite-and their role in the pathogenesis of extrapulmonary tuberculosis-is warranted. Comprehensive immunogenetic studies will contribute to our understanding of tuberculosis pathogenesis, and may allow us to identify persons at highest risk of developing tuberculosis.

\section{Methods}

\section{Study participants}

The study population was pooled from two immunologic studies that have been described previously; the 
inclusion criteria for both studies were similar and are described in detail elsewhere[6,7]. Briefly, patients were identified through the Baltimore City Health Department Eastern Chest Clinic and Nashville Metropolitan Health Department Tuberculosis Clinic. In this casecontrol study, eligibility criteria for case patients included a history of treated culture-confirmed extrapulmonary tuberculosis, age $\geq 18$ years old, and HIV-seronegative status. Extrapulmonary disease was defined as any site outside of the pulmonary parenchyma. Exclusion criteria included serum creatinine $>2 \mathrm{mg} / \mathrm{dL}$, use of corticosteroids or other immunosuppressive agents at the time of diagnosis or time of study entry, malignancy, or diabetes mellitus. The criteria for pulmonary tuberculosis control patients included HIV-seronegative adults $\geq$ 18 years old who had completed treatment for cultureconfirmed pulmonary tuberculosis, and had no evidence of extrapulmonary tuberculosis. Positive cultures of sputum, bronchoalveolar lavage, or pulmonary parenchyma were required. Controls with latent $M$. tuberculosis infection were $\geq 18$ years old, HIV-seronegative, and had a positive tuberculin skin test (defined as $\geq 10 \mathrm{~mm}$ induration after intradermal placement of 5 tuberculin units of PPD) without evidence of active tuberculosis. Participants in this control group were U.S.-born (and therefore not vaccinated with BCG), and were mostly close contacts of tuberculosis cases. Exclusion criteria for both control groups were the same as for the case group. Controls were drawn from the same two clinic populations as cases, and were not related to the cases. Extrapulmonary tuberculosis cases and pulmonary controls completed treatment prior to study entry.

This study was approved by the institutional review boards of the Johns Hopkins Hospital, the Baltimore City Health Department, the National Institutes of Health, Vanderbilt University Medical Center, and the Nashville Metropolitan Health Department. All study participants provided written informed consent.

\section{Sample Collection}

CD4+ lymphocytes were quantified by flow cytometry. DNA was extracted from blood samples using the Puregene DNA Isolation kit (Gentra Systems, Minneapolis, $\mathrm{MN}$ ) following the manufacturer's protocol. Genomic DNA was stored at $-70^{\circ} \mathrm{C}$ until genotyping. Laboratory personnel were blinded to the case-control status of the specimens.

\section{SNP Genotyping}

As of November 15, 2006, 27 SNPs were identified in the literature as being associated with tuberculosis (Table 2). SNPs not included in the GeneChip ${ }^{\circledR}$ Human Mapping 50K Xba Array (see below) were genotyped using validated TaqMan SNP genotyping assays from
Applied Biosystems. For each SNP, 25 ng DNA was used. The polymerase chain reaction (PCR) was performed in an ABI 9700 thermocycler under the following conditions: $95^{\circ} \mathrm{C}$ for 10 minutes followed by 50 cycles of $92^{\circ} \mathrm{C}$ for 15 seconds and $60^{\circ} \mathrm{C}$ for 1 minute. The 384-well plates were read on an ABI 7900HT sequence detection system according to manufacturer's manual. The probes were labeled with FAM or VIC dye at the 5' end and a minor-groove binder and non-fluorescent quencher at the 3 ' end.

\section{Microsatellite Genotyping}

As of November 15, 2006, 3 microsatellites were identified in the literature as being associated with tuberculosis (Table 2). A $5^{\prime}(\mathrm{GT})_{\mathrm{n}}$ microsatellite associated with NRAMP1, a VNTR associated with interleukin (IL)$1 \mathrm{RA}$, and a GT repeat polymorphism in the toll-like receptor (TLR) 2 gene were all genotyped using fluorescent fragment analysis [16]. All 3 microsatellites were amplified by PCR. The PCR primers and conditions for the $5^{\prime}(\mathrm{GT})_{\mathrm{n}}$ and IL-1RA microsatellites were previously reported[17,10]. The TLR2 microsatellite was amplified using the following conditions: 1 minute at $96^{\circ} \mathrm{C} ; 30$ cycles of $94^{\circ} \mathrm{C}$ for 1 minute, 1 minute at $53^{\circ} \mathrm{C}$, and 2 minutes at $70^{\circ} \mathrm{C}$; and a final elongation period of 10 minutes at $70^{\circ} \mathrm{C}$. The primers used to amplify the TLR2 microsatellite were previously published [18]. The forward primers for NRAMP1, IL-1RA and TLR2 microsatellites (5'-ACT CGC ATT AGG CCA ACG AG-3', 5'CTC AGC AAC ACT CCT AT-3', and 5'-GCA TTG CTG AAT GTA TCA GGG A-3' respectively) were all 5' labeled with FAM purchased from MWG Biotech. Following PCR, the amplicons were electrophoresed on a 3730s DNA analyzer (Applied Biosystems) and analyzed with GeneMapper 4.0 (Applied Biosystems).

\section{Candidate Gene Genotyping}

Twenty six candidate genes were identified based on their potential role in tuberculosis immunopathogenesis and the inclusion of SNPs in these genes in the GeneChip ${ }^{\circledR}$ Human Mapping 50K Xba Array (Affymetrix, Inc., Santa Clara, CA). A total of 661 SNPs in these 26 candidate genes were present (Table 4). Genotyping was performed according to the manufacturer's protocol. Briefly, a complexity reduction process was performed where genomic DNA (250 ng) was digested with $X b a \mathrm{I}$, ligated to $X b a \mathrm{I}$ adaptor (Affymetrix), and amplified by polymerase chain reaction (PCR) using primers specific to the ligated adaptor. Cycling conditions were an initial denaturation of $94^{\circ} \mathrm{C}$ for 3 minutes followed by 30 cycles of $94^{\circ} \mathrm{C}$ for 30 seconds, $60^{\circ} \mathrm{C}$ for 45 seconds, and $68^{\circ} \mathrm{C}$ for 60 seconds. A final extension of $68^{\circ} \mathrm{C}$ for 7 minutes concluded the reactions. PCR products were assayed by gel electrophoresis, purified, 
fragmented to $<250 \mathrm{bp}$ using dilute DNaseI (Affymetrix), biotin end-labeled with terminal deoxynucleotidyl transferase, and hybridized to the $50 \mathrm{~K}$ Xba Array at $48^{\circ}$ $\mathrm{C}$ for 16 hours at $60 \mathrm{rpm}$. The hybridized arrays were washed and stained on Fluidics Station 450 and scanned with the GeneChip Scanner according to the manufacturer's settings (Affymetrix). The arrays were analyzed with software GDAS version 3.0.2 (Affymetrix), which provides rank scores for the probability of particular genotypes at SNP loci. The scores were AA or $\mathrm{BB}$ for homozygous alleles and $\mathrm{AB}$ for heterozygous alleles, and confidence scores showed the accuracy of the genotype call. Standard procedures and default analysis parameters for individual DNA samples were employed. An internal control run in parallel did not detect any DNA contamination. All procedures were performed using the same lots of reagents.

\section{Quality Control}

Genotype calling was performed using GDAS version 3.0.2 software as noted above. This software uses the Dynamic Models algorithm for genotype calling [19]. All markers with significant $(\mathrm{P}<0.05$ after Bonferroni correction) departure from Hardy-Weinberg equilibrium were excluded from final analyses. In addition, SNPs in the GeneChip ${ }^{\oplus}$ Human Mapping 50K Xba Array with $<90 \%$ efficiency ( $>10 \%$ missing data) were excluded from the analysis. Missing data patterns did not deviate from random expectations.

\section{Statistical Analysis}

Clinical and demographic characteristics were compared among the three patient groups (extrapulmonary tuberculosis, pulmonary tuberculosis, and PPD+) using the Kruskal-Wallis test for continuous variables and the chisquared and Fisher exact tests for categorical variables. Missing observations were individually excluded from all stages of analyses (for both the univariate and MDR analyses (no imputation was performed).

Two populations were assessed for genetic factors associated with extrapulmonary tuberculosis: 1) all individuals regardless of race; 2) only black participants. This stratified analysis was performed to minimize spurious associations due to population stratification [20]. There were not enough individuals to perform analyses stratified by other racial groups. The two populations were further divided into three subgroups for association analyses: a) any tuberculosis vs. PPD+; b) extrapulmonary tuberculosis vs. PPD+; and c) extrapulmonary vs. pulmonary tuberculosis.

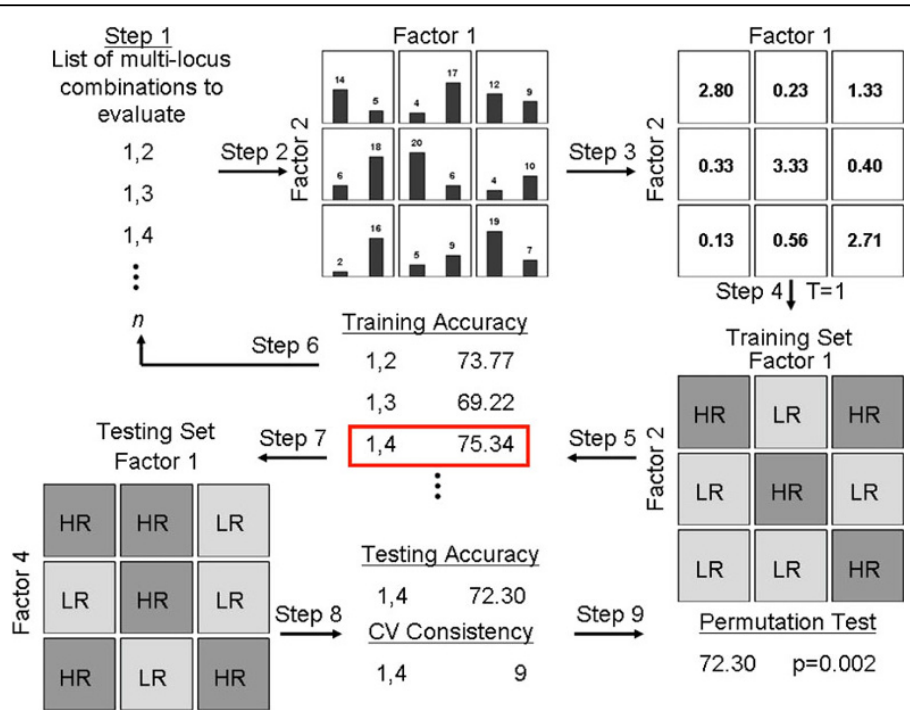

Figure 1 Summary of the general steps to implement the MDR method, adapted from Ritchie and Motsinger 2005 [52]. In step one, the exhaustive list of $n$ combinations are generated from the pool of all independent variables. In step two, for $k=1$ to $N$, the combinations are represented in $k$-dimensional space, and the number of responders and non-responders are counted in each multifactor cell. In step three, the ratio of responders to non-responders is calculated within each cell. In step four, each multifactor cell in the $k$-dimensional space is labeled as high-likelihood/high-risk if the ratio of responsive individuals to non-responsive individuals exceeds a threshold and low-likelihood/low-risk if the threshold is not exceeded. In step five the training accuracy is calculated. This is then repeated for each multifactor combination. In step seven, the model with the best training accuracy is selected and evaluated in the test set. In step eight, the testing accuracy of the model is estimated. In step nine a permutation test is conducted to determine the statistical significance of the model(s). Steps 1 through 6 are repeated for each possible cross-validation interval. Bars represent hypothetical distributions of responders (left) and non-responders (right) with each multifactor combination. Dark-shaded cells represent high-likelihood genotype combinations while light-shaded cells represent low-likelihood genotype combinations. 
Genetic analyses were performed in two stages (see below). Single locus chi-squared association tests (genotypic tests, with 2 degrees of freedom) (STATA version 9.0; College Station, TX) were performed on variants previously reported to be associated with tuberculosis susceptibility. MDR analyses were performed both on previously reported variants and on variants in candidate genes. MDR was performed to explore potential singlelocus associations and gene-gene interactions between variants[21]. Details of the MDR algorithm and implementation are described in the Additional file 1 and Figure 1.

The first stage of the genetic analysis examined variants reported to be associated with tuberculosis susceptibility in previous studies (Table 2). Because each variant represented a distinct statistical hypothesis (since each was being evaluated for replication), no correction for multiple testing was used.

In the second stage of genetic analysis, a nested candidate-gene study was compiled from the Affymetrix Xba genotyping arrays. Only SNPs in genes hypothesized to play a role in tuberculosis pathogenesis were included (see Table 4).

A Linux version of the MDR software was used for data analysis (compiled and benchmarked on a PC with a $600 \mathrm{MHz}$ Pentium-III running Red Hat 2.2.5-15, written in $\mathrm{C}$ and compiled with the GNU C compiler). Presently, MDR software is being distributed in a JAVA version with a graphical user interface http://www.epistasis.org/mdr.html.

For both analysis stages MDR was also performed with genetic factors plus CD4+ lymphocytes and body mass index (BMI). This allowed for exploration of both gene-gene and gene-clinical factor interactions.

Additional file 1: Appendix. Description of the Multifactor Dimensionality Reduction (MDR) Algorithm and its Implementation. Click here for file

[http://www.biomedcentral.com/content/supplementary/1471-2350-1137-S1.DOC ]
Research Center (M01-RR00052 from the National Center for Research Resources, National Institutes of Health), and the Vanderbilt University Department of Medicine.

\section{Author details}

${ }^{1}$ Bioinformatics Research Center, Department of Statistics, North Carolina State University, Raleigh, NC, USA. ²Division of Infectious Diseases, Department of Medicine, Vanderbilt University School of Medicine, Nashville, TN, USA. ${ }^{3}$ Department of Biomedical Informatics, Vanderbilt University School of Medicine, Nashville, TN, USA. ${ }^{4}$ Laboratory of Clinical Infectious Diseases, National Institutes of Health, Bethesda, MD, USA. ${ }^{5}$ Center for Health Services Research, Department of Medicine, Vanderbilt University School of Medicine, Nashville, TN, USA.

\section{Authors' contributions}

AAMR lead the analysis and the writing of the manuscript. PRZA contributed to the design of the study, identification of the genetic polymorphisms to be tested, identification and preparation of the samples to be tested for polymorphisms, and wrote the first draft of the manuscript. NOO contributed to the analysis and the writing of the manuscript. SL oversaw the performance of the genotyping and critically reviewed the manuscript $\mathrm{SMH}$ : contributed to the design of the study and critically reviewed the manuscript. TRS conceived and designed the study, and made significant contributions to the writing of the manuscript. All authors read and approved the final manuscript.

\section{Competing interests}

The authors declare that they have no competing interests.

Received: 26 March 2009

Accepted: 2 March 2010 Published: 2 March 2010

\section{References}

1. Bellamy R, Ruwende C, Corrah T, McAdam KPWJ, Whittle HC, Hill AVS: Variations in the NRAMP1 gene and susceptibility to tuberculosis in West Africans. N Engl J Med 1998, 338:640-644.

2. Bellamy R, Ruwende C, Corrah T, McAdam KP, Thursz M, Whittle HC, Hill AV: Tuberculosis and chronic hepatitis B virus infection in Africans and variation in the vitamin D receptor gene. J Infect Dis 1999, 179:721-724.

3. Comstock GW: Tuberculosis in twins: a re-analysis of the Prophit survey. Am Rev Resp Dis 1978, 117:621-624.

4. Berrington WR, Hawn TR: Mycobacterium tuberculosis, macrophages, and the innate immune response: does common variation matter?. Immunol Rev 2007, 219:167-186.

5. Gonzalez OY, Adams G, Teeter LD, Bui TT, Musser JM, Graviss EA: Extrapulmonary manifestations in a large metropolitan area with a low incidence of tuberculosis. Int J Tuberc Lung Dis 2003, 7:1178-1185.

6. Sterling TR, Dorman SE, Chaisson RE, Ding L, Hackman J, Moore K, Holland SM: HIV-seronegative adults with extrapulmonary tuberculosis have abnormal innate immune responses. Clin Infect Dis 2001, 33:976-982.

7. Antas PRZ, Ding L, Hackman J, Reeves-Hammock L, Shintani AK, Schiffer J, Holland SM, Sterling TR: Decreased CD4+ lymphocytes and innate immune responses in adults with previous extrapulmonary tuberculosis. J Allerg Clin Immunol 2006, 117:916-923.

8. Ritchie MD, Hahn LW, Roodi N, Bailey LR, Dupont WD, Parl FF, Moore JH: Multifactor-dimensionality reduction reveals high-order interactions among estrogen-metabolism genes in sporadic breast cancer. Am J Hum Genet 2001, 69:138-147.

9. Williams SM, Ritchie MD, Phillips JA, Dawson E, Prince M, Dzhura E, Willis A, Semenya A, Summar M, White BC, Addy JH, Kpodonu J, Wong LJ, Felder RA, Jose PA, Moore JH: Multilocus analysis of hypertension: a hierarchical approach. Hum Hered 2004, 57:28-38.

10. Wilkinson RJ, Patel P, Llewelyn M, Hirsch CS, Pasvol G, Snounou G, Davidson RN, Toossi Z: Influence of polymorphism in the genes for the interleukin (IL)-1 receptor antagonist and IL-1beta on tuberculosis. J Exp Med 1999, 189:1863-1874.

11. Wilkinson RJ, Llewelyn M, Toossi Z, Patel P, Pasvol G, Lalvani A, Wright D, Latif M, Davidson RN: Influence of vitamin D deficiency and vitamin D receptor polymorphisms on tuberculosis among Gujarati Asians in west London: a case-control study. Lancet 2000, 355:618-621. 
12. Liu PT, Stenger S, Li H, Wenzel L, Tan BH, Krutzik SR, Ochoa MT, Schauber J, Wu K, Meinken C, Kamen DL, Wagner M, Bals R, Steinmeyer A, Zugel U, Gallo RL, Eisenberg D, Hewison M, Hollis BW, Adams JS, Bloom BR, Modlin RL: Toll-like receptor triggering of a vitamin D-mediated human antimicrobial response. Science 2006, 311:1770-1773.

13. Leung CC, Lam TH, Chan WM, Yew WW, Ho KS, Leung G, Law WS, Tam CM, Chan CK, Chang KC: Lower risk of tuberculosis in obesity. Arch Intern Med 2007, 167:1297-1304.

14. Kong $Y$, Cave MD, Zhang L, Foxman B, Marrs CF, Bates JH, Yang ZH: Association between Mycobacterium tuberculosis Beijing/W lineage strain infection and extrathoracic tuberculosis: Insights from epidemiologic and clinical characterization of the three principal genetic groups of M. tuberculosis clinical isolates. J Clin Microbiol 2007, 45:409-414.

15. Kraft P: Curses-winner's and otherwise-in genetic epidemiology. Epidemiology 2008, 19:649-651.

16. Weber JL, May PE: Abundant class of human DNA polymorphisms which can be typed using the polymerase chain reaction. Am J Hum Genet 1989, 44:388-396.

17. Soborg C, Andersen AB, Madsen HO, Kok-Jensen A, Skinhoj P, Garred P: Natural resistance-associated macrophage protein 1 polymorphisms are associated with microscopy-positive tuberculosis. J Infect Dis 2002, 186:517-521.

18. Yim JJ, Lee HW, Lee HS, Kim YW, Han SK, Shim YS, Holland SM: The association between microsatellite polymorphisms in intron II of the human Toll-like receptor 2 gene and tuberculosis among Koreans. Genes Immun 2006, 7:150-155.

19. Di X, Matsuzaki H, Webster TA, Hubbell E, Liu G, Dong S, Bartell D, Huang J, Chiles R, Yang G, Shen MM, Kulp D, Kennedy GC, Mei R, Jones KW, Cawley S: Dynamic model based algorithms for screening and genotyping over $100 \mathrm{~K}$ SNPs on oligonucleotide microarrays. Bioinformatics 2005, 21:1958-1963.

20. Reich DE, Goldstein DB: Detecting association in a case-control study while correcting for population stratification. Genet Epidemiol 2001, 20:4-16

21. Motsinger AA, Ritchie MD: The effect of reduction in cross-validation intervals on the performance of multifactor dimensionality reduction. Genet Epidemiol 2006, 30:546-555.

22. Awomoyi AA, Marchant A, Howson JM, McAdam KP, Blackwell JM, Newport MJ: Interleukin-10, polymorphism in SLC11A1 (formerly NRAMP1), and susceptibility to tuberculosis. J Infect Dis 2002, 186:1808-1814.

23. Hoal EG, Lewis LA, Jamieson SE, Tanzer F, Rossouw M, Victor $T$, Hillerman $R$, Beyers N, Blackwell JM, van Helden PD: SLC11A1 (NRAMP1) but not SLC11A2 (NRAMP2) polymorphisms are associated with susceptibility to tuberculosis in a high-incidence community in South Africa. Int I Tuberc Lung Dis 2004, 8:1464-1471.

24. Gao PS, Fujishima S, Mao XQ, Remus N, Kanda M, Enomoto T, Dake Y, Bottini N, Tabuchi M, Hasegawa N, Yamaguchi K, Tiemessen C, Hopkin JM, Shirakawa T, Kishi F: Genetic variants of NRAMP1 and active tuberculosis in Japanese populations. International Tuberculosis Genetics Team. Clin Genet 2000, 58:74-76.

25. Ma X, Dou S, Wright JA, Reich RA, Teeter LD, El Sahly HM, Awe RJ, Musser JM, Graviss EA: 5' dinucleotide repeat polymorphism of NRAMP1 and susceptibility to tuberculosis among Caucasian patients in Houston, Texas. Int J Tuberc Lung Dis 2002, 6:818-823.

26. Li HT, Zhang TT, Zhou YQ, Huang QH, Huang J: SLC11A1 (formerly NRAMP1) gene polymorphisms and tuberculosis susceptibility: a metaanalysis. Int J Tuberc Lung Dis 2006, 10:3-12.

27. Ryu S, Park YK, Bai GH, Kim SJ, Park SN, Kang S: 3'UTR polymorphisms in the NRAMP1 gene are associated with susceptibility to tuberculosis in Koreans. Int J Tuberc Lung Dis 2000, 4:577-580.

28. Liu W, Cao WC, Zhang CY, Tian L, Wu XM, Habbema JD, Zhao QM, Zhang PH, Xin ZT, Li CZ, Yang H: VDR and NRAMP1 gene polymorphisms in susceptibility to pulmonary tuberculosis among the Chinese Han population: a case-control study. Int J Tuberc Lung Dis 2004, 8:428-434.

29. Malik S, Abel L, Tooker H, Poon A, Simkin L, Girard M, Adams GJ, Starke JR, Smith KC, Graviss EA, Musser JM, Schurr E: Alleles of the NRAMP1 gene are risk factors for pediatric tuberculosis disease. Proc Natl Acad Sci USA 2005, 102:12183-12188.
30. Tosh K, Campbell SJ, Fielding K, Sillah J, Bah B, Gustafson P, Manneh K, Lisse I, Sirugo G, Bennett S, Aaby P, McAdam KP, Bah-Sow O, Lienhardt C, Kramnik I, Hill AV: Variants in the SP110 gene are associated with genetic susceptibility to tuberculosis in West Africa. Proc Natl Acad Sci USA 2006, 103:10364-10368.

31. Lio D, Marino V, Serauto A, Gioia V, Scola L, Crivello A, Forte Gl, ColonnaRomano G, Candore G, Caruso C: Genotype frequencies of the $+874 \mathrm{~T}->\mathrm{A}$ single nucleotide polymorphism in the first intron of the interferongamma gene in a sample of Sicilian patients affected by tuberculosis. Eur I Immunogenet 2002, 29:371-374.

32. Rossouw M, Nel HJ, Cooke GS, van Helden PD, Hoal EG: Association between tuberculosis and a polymorphic NFkappaB binding site in the interferon gamma gene. Lancet 2003, 361:1871-1872.

33. Lopez-Maderuelo D, Arnalich F, Serantes R, Gonzalez A, Codoceo R, Madero R, Vazquez JJ, Montiel C: Interferon-gamma and interleukin-10 gene polymorphisms in pulmonary tuberculosis. Am J Respir Crit Care Med 2003, 167:970-975.

34. Henao Ml, Montes C, Paris SC, Garcia LF: Cytokine gene polymorphisms in Colombian patients with different clinical presentations of tuberculosis. Tuberculosis (Edinb) 2006, 86:11-19.

35. Tso HW, Ip WK, Chong WP, Tam CM, Chiang AK, Lau YL: Association of interferon gamma and interleukin 10 genes with tuberculosis in Hong Kong Chinese. Genes Immun 2005, 6:358-363.

36. Cooke GS, Campbell SJ, Sillah J, Gustafson P, Bah B, Sirugo G, Bennett S, McAdam KP, Sow O, Lienhardt C, Hill AV: Polymorphism within the interferon-gamma/receptor complex is associated with pulmonary tuberculosis. Am J Respir Crit Care Med 2006, 174:339-343.

37. Amirzargar AA, Rezaei N, Jabbari H, Danesh AA, Khosravi F, Hajabdolbaghi M, Yalda A, Nikbin B: Cytokine single nucleotide polymorphisms in Iranian patients with pulmonary tuberculosis. Eur Cytokine Netw 2006, 17:84-89.

38. Gomez LM, Camargo JF, Castiblanco J, Ruiz-Narvaez EA, Cadena J, Anaya JM: Analysis of IL1B, TAP1, TAP2 and IKBL polymorphisms on susceptibility to tuberculosis. Tissue Antigens 2006, 67:290-296.

39. Awomoyi AA, Charurat M, Marchant A, Miller EN, Blackwell JM, MCAdam KP, Newport MJ: Polymorphism in IL1B: IL1B-511 association with tuberculosis and decreased lipopolysaccharide-induced IL-1 beta in IFNgamma primed ex-vivo whole blood assay. J Endotoxin Res 2005, 11:281-286

40. Bellamy R, Ruwende C, Corrah T, McAdam KP, Whittle HC, Hill AV: Assessment of the interleukin 1 gene cluster and other candidate gene polymorphisms in host susceptibility to tuberculosis. Tuber Lung Dis 1998, 79:83-89.

41. Delgado JC, Baena A, Thim S, Goldfeld AE: Ethnic-specific genetic associations with pulmonary tuberculosis. J Infect Dis 2002, 186:1463-1468

42. Oral HB, Budak F, Uzaslan EK, Basturk B, Bekar A, Akalin H, Ege E, Ener B, Goral G: Interleukin-10 (IL-10) gene polymorphism as a potential host susceptibility factor in tuberculosis. Cytokine 2006, 35:143-147.

43. Shin HD, Park BL, Kim YH, Cheong HS, Lee IH, Park SK: Common interleukin 10 polymorphism associated with decreased risk of tuberculosis. Exp Mol Med 2005, 37:128-132.

44. Soborg C, Madsen HO, Andersen AB, Lillebaek T, Kok-Jensen A, Garred P. Mannose-binding lectin polymorphisms in clinical tuberculosis. J Infect Dis 2003, 188:777-782.

45. Bornman L, Campbell SJ, Fielding K, Bah B, Sillah J, Gustafson P, Manneh K, Lisse I, Allen A, Sirugo G, Sylla A, Aaby P, McAdam KP, Bah-Sow O, Bennett S, Lienhardt C, Hill AV: Vitamin D receptor polymorphisms and susceptibility to tuberculosis in West Africa: a case-control and family study. J Infect Dis 2004, 190:1631-1641.

46. Flores-Villanueva PO, Ruiz-Morales JA, Song CH, Flores LM, Jo EK, Montano M, Barnes PF, Selman M, Granados J: A functional promoter polymorphism in monocyte chemoattractant protein-1 is associated with increased susceptibility to pulmonary tuberculosis. J Exp Med 2005, 202:1649-1658.

47. Hawn TR, Dunstan SJ, Thwaites GE, Simmons CP, Thuong NT, Lan NT, Quy HT, Chau TT, Hieu NT, Rodrigues S, Janer M, Zhao LP, Hien TT, Farrar JJ, Aderem A: A polymorphism in Toll-interleukin 1 receptor domain containing adaptor protein is associated with susceptibility to meningeal tuberculosis. J Infect Dis 2006, 194:1127-1134. 
48. Ogus AC, Yoldas B, Ozdemir T, Uguz A, Olcen S, Keser I, Coskun M, Cilli A, Yegin O: The Arg753GLn polymorphism of the human toll-like receptor 2 gene in tuberculosis disease. Eur Respir J 2004, 23:219-223.

49. Ben-Ali M, Barbouche MR, Bousnina S, Chabbou A, Dellagi K: Toll-like receptor 2 Arg677Trp polymorphism is associated with susceptibility to tuberculosis in Tunisian patients. Clin Diagn Lab Immunol 2004, 11:625-626.

50. Li CM, Campbell SJ, Kumararatne DS, Bellamy R, Ruwende C, MCAdam KP, Hill AV, Lammas DA: Association of a polymorphism in the P2X7 gene with tuberculosis in a Gambian population. J Infect Dis 2002, 186:1458-1462.

51. Fernando SL, Saunders BM, Sluyter R, Skarratt KK, Goldberg H, Marks GB, Wiley JS, Britton WJ: A polymorphism in the P2X7 gene increases susceptibility to extrapulmonary tuberculosis. Am J Respir Crit Care Med 2007, 175:360-366.

52. Ritchie MD, Motsinger AA: Multifactor dimensionality reduction for detecting gene-gene and gene-environment interactions in pharmacogenomics studies. Pharmacogenomics 2005, 6:823-834.

Pre-publication history

The pre-publication history for this paper can be accessed here:http://www biomedcentral.com/1471-2350/11/37/prepub

doi:10.1186/1471-2350-11-37

Cite this article as: Motsinger-Reif et al:: Polymorphisms in IL-1 $\beta$, vitamin

$\mathrm{D}$ receptor Fok1, and Toll-like receptor 2 are associated with

extrapulmonary tuberculosis. BMC Medical Genetics 2010 11:37.

\section{Submit your next manuscript to BioMed Central and take full advantage of:}

- Convenient online submission

- Thorough peer review

- No space constraints or color figure charges

- Immediate publication on acceptance

- Inclusion in PubMed, CAS, Scopus and Google Scholar

- Research which is freely available for redistribution

Submit your manuscript at www.biomedcentral.com/submit 